BERKALA FISIKA INDONESIA

\title{
Tingkat kelayakan media pembelajaran cahaya berbasis contextual teaching and learning dengan videoscribe
}

\author{
Widarti Sri Wahyuni ${ }^{1 *}$, Dwi Sulisworo ${ }^{2}$ \\ ${ }^{1}$ Pendidikan Fisika, Fakultas Keguruan dan Ilmu Pendidikan, Universitas Ahmad Dahlan, Indonesia \\ 2 Magister Pendidikan Fisika, Fakultas Keguruan dan Ilmu Pendidikan, Universitas Ahmad Dahlan, Indonesia \\ Email: wdwahyuni88@gmail.com* \\ * Penulis korespondensi
}

\begin{tabular}{l}
\hline Informasi artikel \\
\hline Sejarah artikel: \\
Dikirim \\
Revisi \\
Diterima \\
\hline
\end{tabular}

\section{Kata kunci:}

Animasi

Media pembelajaran

Pembelajaran kontekstual

Strategi pembelajaran

Videoscribe

\section{ABSTRAK}

Aplikasi perkembangan media pembelajaran sekarang ini menunjukkan kemajuan yang sangat pesat, salah satunya adalah Videoscribe. Media ini merupakan media berbentuk video, dengan karakteristik tampilan yang menarik berupa animasi bentuk tangan yang sedang menggambar atau menuliskan pesan. Adapun penelitian ini mempunyai tujuan mengembangkan media pembelajaran yang layak berbasis CTL dengan menggunakan Videoscribe pada pokok bahasan cahaya kelas VIII. Penelitian ini merupakan penelitian pengembangan dengan tahapan identifikasi potensi masalah, pengumpulan data, perancangan media, validasi media oleh ahli, dan ujicoba pada siswa (20 siswa). Berdasarkan hasil validasi oleh ahli media, ahli materi, guru, dan respon siswa, media yang dikembangkan dinyatakan layak dengan tingkat kelayakan $73 \%$ dari ahli media, $82 \%$ dari ahli materi, $92 \%$ dari guru, dan $85 \%$ dari siswa. Dapat disimpulkan bahwa media ini layak digunakan untuk menunjang kegiatan belajar pada pokok bahasan cahaya.
\end{abstract}

This is an open access article under the CC-BY-SA license

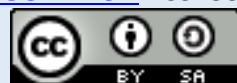

\section{Keywords:}

Animations

Instructional Media

Contextual teaching and

learning

Learning strategies

Videoscribe

\section{ABSTRACT}

The feasibility level of light learning media based on contextual teaching and learning with videoscribe. Application of learning media development is currently showing very rapid progress, one of which is Videoscribe. This media is a video-shaped media, with attractive display characteristics in an animated hand drawing or writing a message. This research aims to develop a viable learning media based on CTL using Videoscribe on the subject of light in class VIII. This research is development research with identifying potential problems, collecting data, designing media, validating media by experts, and testing students (20 students). Based on the validation results by media experts, material experts, teachers, and student responses, the media developed was declared feasible with an eligibility level of $73 \%$ from media experts, $82 \%$ from material experts, $92 \%$ from teachers, and $85 \%$ from students. It can be concluded that this media is suitable for use to support learning activities on the subject of light.
\end{abstract}

\section{How to Cite:}

Wahyuni, W. S., \& Sulisworo, D. (2021). Tingkat kelayakan media pembelajaran cahaya berbasis contextual teaching and learning dengan videoscribe. Berkala Fisika Indonesia: Jurnal Ilmiah Fisika, Pembelajaran dan Aplikasinya, 12(1), 12-19. 


\section{Pendahuluan}

Pendidikan adalah upaya yang disengaja dan terorganisir untuk membangun lingkungan belajar dalam konteks proses pembelajaran terstruktur yang diadakan di ruang kelas. Strategi dan alat instruksional guru dalam proses pembelajaran adalah dua faktor yang memainkan peran penting dalam penyampaian pembelajaran. Tingkat pendidikan di sekolah dapat ditingkatkan dengan menggunakan strategi pembelajaran dan alat peraga yang efektif. (Angkowo \& Kosasih, 2007; Susilana \& Riyana, 2008). Guru, di sisi lain, menghadapi beberapa tantangan dalam meningkatkan efisiensi pendidikan. Meskipun kemampuan siswa untuk memperoleh konten berpengaruh signifikan terhadap kinerja pembelajaran, hal yang paling menantang adalah mendorong persiapan pembelajaran. Akibatnya, guru harus memprioritaskan peningkatan standar pendidikan untuk meningkatkan kesiapan belajar siswa.

Penggunaan media pembelajaran yang digunakan di dalam kelas juga merupakan salah satu cara yang sangat membantu guru dalam menumbuhkan minat belajar siswa (Nurrita, 2018; Supriyono, 2018), terutama untuk siswa yang dirasa kurang mampu menerima materi pembelajaran dengan cepat maupun hanya dengan mendengar. Dimasukkannya alat bantu media pembelajaran dinilai dapat membuat pikiran siswa lebih siap terstimulasi. Selain itu, media pembelajaran dapat memberikan pemahaman yang lebih baik kepada siswa tentang mata pelajaran yang dipahami, baik secara visual maupun audiovisual (Hayati, Ahmad, \& Harianto, 2017).

Dalam proses belajar mengajar, penggunaan media dalam pembelajaran dapat menghasilkan dorongan dan minat baru, memotivasi dan menstimulasi kebiasaan belajar, serta berdampak psikologis pada siswa. Penggunaan media pembelajaran pada tahap orientasi akan sangat membantu kemajuan proses pembelajaran dan menunjukkan tugas dan isi pengetahuan. Selain itu, media pembelajaran memfasilitasi kemampuan siswa dalam meningkatkan pemahaman, mengelola data dengan cara yang menarik dan akurat, menganalisis, dan memadatkan informasi.

Videoscribe merupakan salah satu media pembelajaran yang digunakan untuk mendorong keterlibatan siswa dalam pembelajaran (Aryuntini, Astuti, \& Yuliana, 2018; Matematika, 2018; Yusup, Aini, \& Pertiwi, 2016). Videoscribe adalah alat pembelajaran multimedia animasi yang menggabungkan banyak gambar menjadi satu video. Videoscribe akan menyampaikan konten pembelajaran kepada siswa menggunakan kombinasi visual, suara, dan desain yang menarik, memungkinkan mereka untuk menikmati proses pembelajaran (Rahmawati, W.W, \& Kardi, 2017; Yusup et al., 2016).

Permasalahan pembelajaran yang ditemui adalah terkait kesiapan siswa dalam menerima pembelajaran yang diberikan belum optimal. Hal ini dibuktikan dengan ketidakmampuan siswa dalam memperhatikan langkah-langkah pembelajaran dan tidak yakinnya siswa dalam mematuhi prosedur pembelajaran. Selain itu, belum banyak digunakan media pembelajaran yang praktis, yang dapat diakses oleh siswa dimanapun mereka berada, sehingga diperlukan media pembelajaran yang mampu merangsang siswa untuk memperhatikan pokok bahasan yang sedang disampaikan. 
Di sisi lain, penggunaan strategi pembelajaran yang lebih berorientasi pada Student-Centered Learning akan dapat meningkatkan kinerja pembelajaran. Salah satu strategi adalah dengan menggunakan pendekatan Contextual Teaching and Learning (CTL). Pendekatan ini dilakukan dengan mengaitkan materi pelajaran dengan berbagai fenomena yang ada dalam kehidupan nyata (Johnson, 2002; Sears, 2002). Banyak riset yang mendukung temuan bahwa penerapan CTL ini dapat dilakukan pada pembelajaran sains (Hendawati et al., 2019; Kurniasari, Sukarmin, \& Sarwanto, 2018; Maynastiti, Serevina, \& Sugihartono, 2020; Selvianiresa \& Prabawanto, 2017; Suryawati \& Osman, 2017; Susialita, 2016; Yuwandra \& Arnawa, 2020). Oleh karena itu, penelitian ini bertujuan untuk mengembangkan media pembelajaran berbasis CTL dengan Videoscribe pada pokok bahasan cahaya kelas VIII.

\section{Metode}

Penelitian ini merupakan penelitian pengembangan dengan tahapan identifikasi potensi masalah, pengumpulan data, perancangan media, validasi media oleh ahli, dan ujicoba pada siswa (Sugiyono, 2015). Materi yang dikembangkan dalam media ini adalah cahaya untuk siswa kelas VIII. Ahli materi, media, dan guru berkolaborasi dalam melakukan validasi terhadap media yang dikembangkan. Media yang telah valid selanjutnya diuji coba pada siswa kelas VIII di sebuah SMP di Kabupaten Bantul. Data angket selanjutnya dikonversi menjadi persentase dan dikategorikan sesuai dengan Tabel 1.

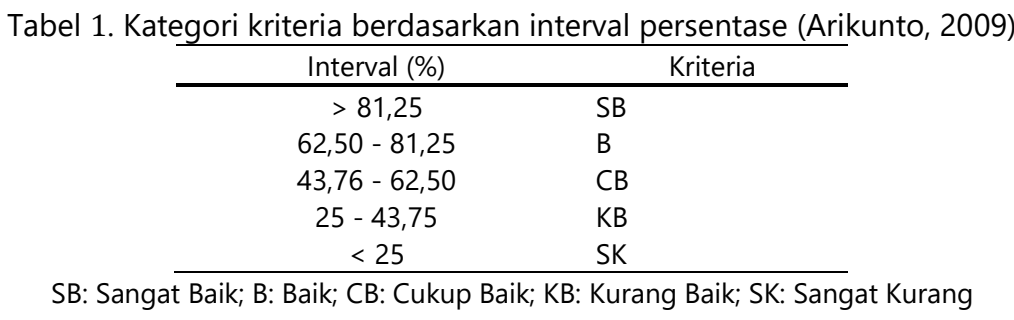

\section{Hasil dan Pembahasan}

Peneliti mengangkat potensi masalah yang terdapat di sekolah dimana penggunaan media pembelajaran belum bervariasi dan belum digunakan secara maksimal, sehingga siswa cenderung kurang memperhatikan apa yang disampaikan guru dan akibatnya siswa menjadi kurang paham dengan mata pelajaran yang diberikan. Data yang diperoleh peneliti merupakan hasil dari observasi ketika peneliti melakukan kegiatan magang dasar, magang terapan, dan magang lanjut di sekolah. Kegiatan tersebut menghasilkan informasi yang benar dan terkini, yang kemudian digunakan untuk mempersiapkan pembuatan media pembelajaran berbasis Videoscribe.

Tahap desain dilakukan dengan membuat rancangan produk berupa storyboard. Storyboard merupakan naskah visual yang dijadikan acuan dalam pengembangan media pembelajaran. Storyboard menggambarkan secara garis besar penataan gambar dan materi. Rancangan storyboard yang telah dibuat, dilanjutkan dengan menentukan komposisi warna, jenis huruf, pengumpulan gambar, dan materi. Penentuan komposisi, baik warna, jenis huruf, materi dan gambar disesuaikan dengan 
background media pembelajaran agar tidak kontras, sehingga tidak menyebabkan mata lelah ataupun merasa bosan ketika media pembelajaran dijalankan. Gambar dan materi yang dimasukkan dalam media pembelajaran diperoleh dari berbagai sumber baik itu media online maupun dari berbagai macam buku referensi yang diharapkan dapat membuat siswa tertarik untuk memperhatikan materi pembelajaran yang disampaikan. Produk yang telah dibuat ditunjukkan pada Gambar 1, Gambar 2 dan Gambar 3.

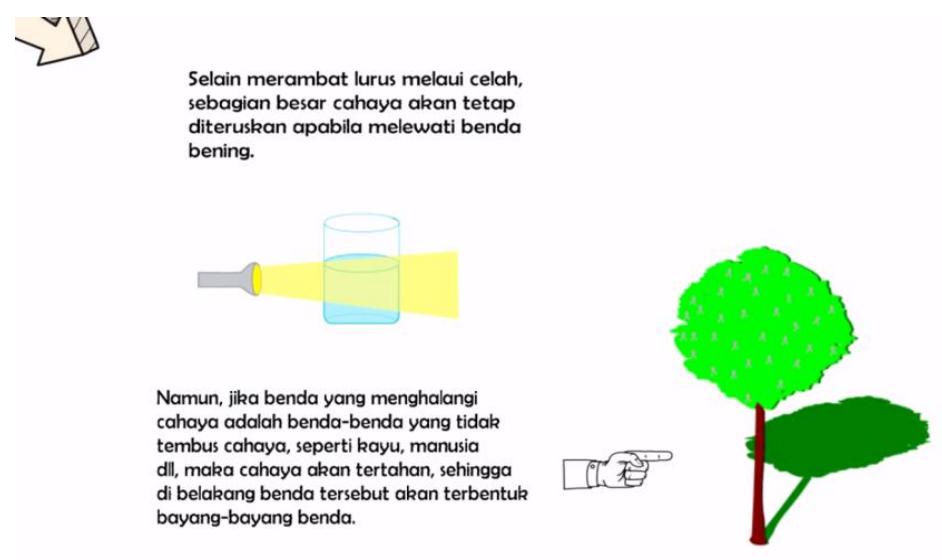

Gambar 1. Penjelasan pembentukan bayangan benda
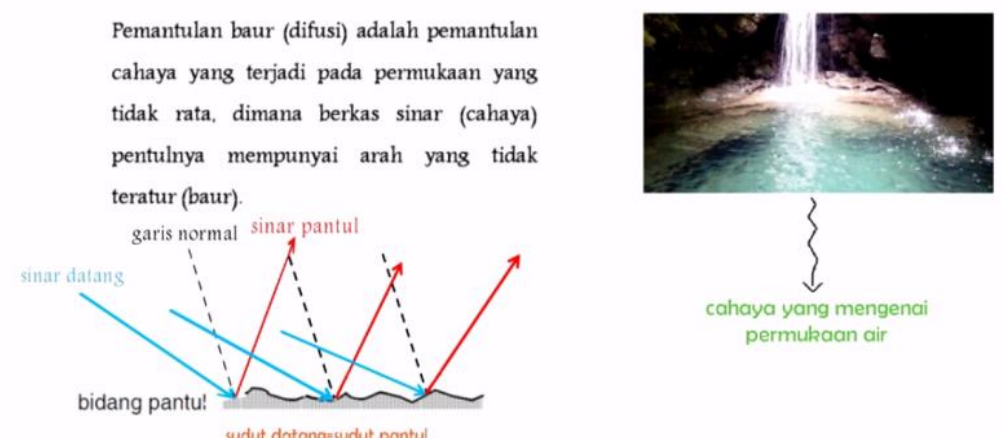

Gambar 2. Penjelasan pembiasan baur dalam kehidupan sehari-hari

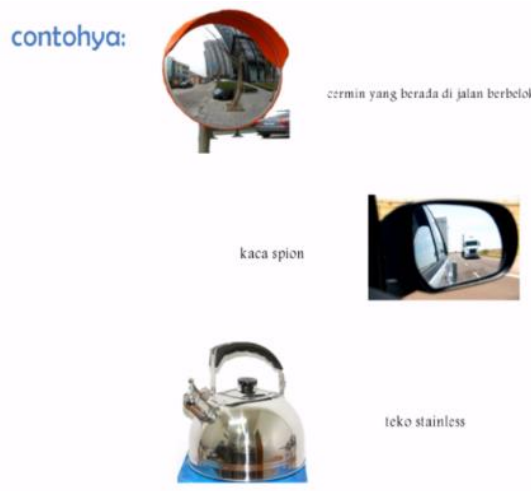

Gambar 3. Penerapan cermin cembung

Validator kemudian menguji produk yang dihasilkan agar layak digunakan sebagai sarana pembelajaran dalam meningkatkan pemahaman siswa. Ahli media, ahli materi, dan guru merupakan 
validator. Dalam laporan ini ada dua orang ahli media. Ahli media mendemonstrasikan dan menguji videoscribe untuk divalidasi. Tabel 2 menunjukkan hasil validasi ahli media.

Tabel 2. Hasil validasi oleh ahli media

\begin{tabular}{llccccc}
\hline No & $\begin{array}{c}\text { Aspek yang } \\
\text { dinilai }\end{array}$ & \multicolumn{2}{c}{ Nilai } & $\begin{array}{c}\text { Nilai } \\
\text { Maksimal }\end{array}$ & $\begin{array}{c}\text { Persentase } \\
\text { Keidealan }\end{array}$ & \multirow{2}{*}{ Kriteria } \\
\cline { 3 - 4 } & Ahli I & Ahli II & & \\
\hline 1 & Mutu Teknis & 15 & 14 & 20 & $72,50 \%$ & B \\
2 & Media & 36 & 39 & 52 & $72 \%$ & B \\
\hline \multicolumn{7}{c}{ Ket: B = Baik }
\end{tabular}

Berdasarkan Tabel 2, diperoleh hasil penilaian dalam bentuk persentase pada aspek mutu teknis adalah sebesar $72,5 \%$, serta dari aspek media sebesar $72 \%$. Temuan ini menunjukkan bahwa media pembelajaran tentang cahaya termasuk dalam kategori Baik ditinjau dari segi mutu teknis dan aspek media.

Media pembelajaran berbasis Videoscribe divalidasi oleh ahli materi dan hasilnya ditunjukkan dalam Tabel 3.

Tabel 3. Hasil validasi oleh ahli materi

\begin{tabular}{|c|c|c|c|c|c|c|}
\hline \multirow[t]{2}{*}{ No } & \multirow{2}{*}{ Aspek yang dinilai } & \multicolumn{2}{|c|}{ Nilai } & \multirow{2}{*}{$\begin{array}{c}\text { Nilai } \\
\text { Maksimal }\end{array}$} & \multirow{2}{*}{$\begin{array}{c}\text { Persentase } \\
\text { Keidealan }\end{array}$} & \multirow{2}{*}{ Kriteria } \\
\hline & & Ahli I & Ahli II & & & \\
\hline 1 & Konsep & 10 & 8 & 12 & $75 \%$ & $B$ \\
\hline 2 & Kesesuaian Materi & 14 & 13 & 16 & $84 \%$ & SB \\
\hline 3 & Penyajian Materi & 20 & 20 & 24 & $83,30 \%$ & SB \\
\hline 4 & Kelayakan Isi & 14 & 13 & 16 & $84,3 \%$ & SB \\
\hline 5 & Kompetensi & 9 & 9 & 12 & $75 \%$ & $\mathrm{~B}$ \\
\hline
\end{tabular}

Hasil validasi dari ahli materi ditampilkan dalam Tabel 3. Aspek konsep memiliki kategori Baik dengan persentase sebesar $75 \%$. Aspek kesesuaian materi termasuk dalam kategori sangat baik yaitu 84\%. Penyajian materi mendapat skor 83,3\%, termasuk dalam kategori sangat baik. Aspek isi kelayakan sebesar $84,3 \%$ dengan kategori sangat baik. Aspek kompetensi sebesar $75 \%$ dengan kategori baik. Hasil uji kelayakan menunjukkan bahwa media pembelajaran berbasis videoscribe pada topik cahaya dalam kategori baik atau layak digunakan.

Guru berperan sebagai ahli pendidik yang dapat mengetahui kondisi yang ada di lapangan pada saat proses pembelajaran fisika berlangsung. Pengguna pada penelitian ini adalah satu orang guru fisika di sekolah. Adapun hasil penilaian guru terhadap media pembelajaran ini ditunjukkan pada Tabel 4. Berdasarkan penilaian pada Tabel 4, didapatkan hasil dalam bentuk persentase yaitu pada aspek bahasa sebesar $83 \%$ dengan kategori sangat baik, aspek isi sebesar $91 \%$ dengan kategori sangat baik, dan aspek kesesuaian materi sebesar $100 \%$ dengan kategori sangat baik. Produk yang dinilai oleh guru merupakan produk yang telah direvisi setelah divalidasi oleh ahli media dan ahli materi. 
Tabel 4. Hasil penilaian pengguna

\begin{tabular}{llcccc}
\hline No & Aspek yang dinilai & $\begin{array}{c}\text { Nilai } \\
\text { Pengguna }\end{array}$ & $\begin{array}{c}\text { Nilai } \\
\text { Maksimal }\end{array}$ & $\begin{array}{c}\text { Persentase } \\
\text { Keidealan }\end{array}$ & Kriteria \\
\hline 1 & Bahasa & 10 & 12 & $75 \%$ & SB \\
2 & Isi & 29 & 32 & $84 \%$ & SB \\
3 & Kesesuaian Materi & 16 & 16 & $83,30 \%$ & SB \\
\hline \multicolumn{5}{r}{ Ket: SB = Sangat baik }
\end{tabular}

Produk yang telah divalidasi selanjutnya diujicobakan kepada siswa kelas VIII A dan B dengan jumlah responden adalah 20 siswa yang dipilih secara acak. Adapun hasil respon siswa terhadap media pembelajaran ditunjukkan pada Tabel 5. Berdasarkan penilaian pada Tabel 5, masing-masing aspek dalam kategori sangat baik. Persentase aspek ketertarikan, kejelasan makna, keaktifan siswa, penyajian materi, pemahaman siswa, dan isi masing-masing sebesar $89 \%, 83 \%, 87 \%, 86 \%, 82 \%$, dan $88 \%$.

Tabel 5. Respon siswa terhadap media pembelajaran

\begin{tabular}{clccl}
\hline No & Aspek yang dinilai & Nilai Maksimal & Persentase Keidealan & Kriteria \\
\hline 1 & Ketertarikan & 12 & $89 \%$ & SB \\
2 & Kejelasan makna & 16 & $83 \%$ & SB \\
3 & Keaktifan siswa & 8 & $87 \%$ & SB \\
4 & Penyajian materi & 12 & $86 \%$ & SB \\
5 & Pemahaman siswa & 16 & $82 \%$ & SB \\
6 & Isi & 16 & $88 \%$ & SB \\
\hline \multicolumn{5}{c}{ Ket: SB = Sangat baik }
\end{tabular}

Media pembelajaran yang dikembangkan dalam upaya meningkatkan pemahaman siswa kelas VIII pada pokok bahasan cahaya merupakan media pembelajaran berbasis CTL yang berbentuk video. Media pembelajaran telah divalidasi oleh ahli media, ahli materi, serta Pengguna dan dikatakan layak untuk diujicobakan pada responden. Hasil penilaian terhadap media pembelajaran berbasis videoscribe secara keseluruhan dapat dilihat pada Gambar 4.

Berdasarkan hasil dari respon siswa pada Gambar 4, dapat diketahui bahwa media pembelajaran yang dikembangkan oleh peneliti yang telah divalidasi oleh ahli media dan ahli meteri dapat digunakan untuk menunjang kegiatan belajar mengajar siswa kelas VIII terhadap pokok bahasan cahaya. Media pembelajaran yang dikembangkan memiliki beberapa karakteristik, diantaranya adalah dapat digunakan siswa sebagai sumber untuk belajar mandiri karena mudah dibawa kemana-mana. Selain itu, media ini juga dapat digunakan sebagai sarana untuk menunjang kegiatan belajar mengajar. Media yang dikembangkan berupa video yang menampilkan materi cahaya dan ilustrasi dari kehidupan seharihari yang dapat dilihat di komputer atau ponsel. 


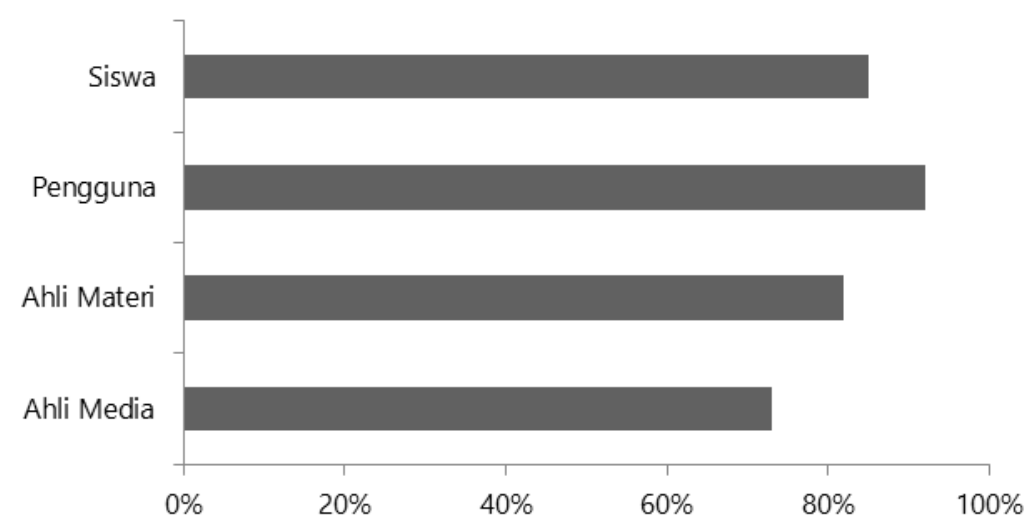

Gambar 4. Ringkasan Penilaian Kelayakan Media Pembelajaran

Kelebihan dari media pembelajaran ini adalah fleksibel, karena dapat disimpan dalam telepon genggam, dibawa kapan saja, di mana saja dan oleh siapa saja (Cavalcante, Riberas, \& Rosa, 2016; Yusup et al., 2016). Media ini juga baik untuk semua yang sedang belajar dengan cara mendengar dan melihat yang dapat menampilkan gambar, grafik, atau diagram sesuai dengan temuan dari (Rahmawati et al., 2017). Media pembelajaran yang telah dikembangkan selanjutnya disebarluaskan kepada peserta didik dan pihak sekolah. Selain itu media pembelajaran dapat dibagikan melalui media online ataupun gadget.

\section{Simpulan}

Berdasarkan hasil penelitian dan pengembangan yang telah dilakukan dapat diperoleh kesimpulan bahwa media pembelajaran berbasis CTL dengan Videoscribe pada pokok bahasan cahaya kelas VIII layak digunakan dengan kriteria Sangat Baik berdasar validasi ahli media, ahli materi, dan guru. Ujicoba pada siswa juga memberikan respon yang tinggi dalam kategori sangat baik. Dengan demikian, media ini layak digunakan untuk menunjang kegiatan belajar mengajar siswa pada pokok bahasan cahaya kelas VIII.

Beberapa hal yang perlu diperhatikan dalam penerapan media ini di antaranya adalah perlunya pemahaman peran guru dalam pembelajaran. Guru sebagai fasilitator pembelajaran hendaknya dalam penggunaan media dapat menciptakan suasana pembelajaran yang lebih kreatif dan inovatif serta mampu lebih menarik perhatian siswa dalam memperhatikan pembelajaran yang sedang disampaikan. Kemanfaatan yang lebih luas dapat dilakukan dengan menyebarluaskan produk ini pada berbagai kanal online.

\section{References}

Arikunto, S. (2009). Manajemen penelitian. Jakarta: Rineka Cipta.

Aryuntini, N., Astuti, I., \& Yuliana, Y. G. S. (2018). Development of learning media based on videoscribe to improve writing skill for descriptive text of english language study. Journal of Education, Teaching and Learning, 3(2), 187-194. 
Cavalcante, M. T. L., Riberas, G., \& Rosa, G. (2016). Fostering innovation in social work and social education degrees: multilingual environment and tools for social change. International Journal of Educational Technology in Higher Education, 13(1), 31-41.

Hayati, N., Ahmad, M. Y., \& Harianto, F. (2017). Hubungan penggunaan media pembelajaran audio visual dengan minat peserta didik pada pembelajaran pendidikan agama islam di SMAN 1 Bangkinang Kota. Jurnal AlHikmah, 14(2), 160-180.

Hendawati, Y., Pratomo, S., Suhaedah, S., Lestari, N. A., Ridwan, T., \& Majid, N. W. A. (2019). Contextual teaching and learning of physics at elementary school. Journal of Physics: Conference Series, 1318, 012130.

Johnson, E. B. (2002). Contextual teaching and learning: What it is and why it's here to stay. California: Corwin Press.

Kurniasari, H., Sukarmin, \& Sarwanto. (2018). Development of contextual teaching and learning based science module for junior high school for increasing creativity of students. Journal of Physics: Conference Series, 983, 012035.

Pamungkas, A. S., Ihsanudin, I., Novaliyosi, N., \& Yandari, I. A. V. (2018). Video pembelajaran berbasis sparkol videoscribe: Inovasi pada perkuliahan sejarah matematika. Prima: Jurnal Pendidikan Matematika, 2(2), 127135.

Maynastiti, D., Serevina, V., \& Sugihartono, I. (2020). The development of flip book contextual teaching and learningbased to enhance students' physics problem solving skill. Journal of Physics: Conference Series, 1481, 012076.

Nurrita, T. (2018). Pengembangan media pembelajaran untuk meningkatkan hasil belajar siswa. Misykat, 3(1), 171187.

Rahmawati, F., W.W, S., \& Kardi, S. (2017). Pengembangan perangkat pembelajaran fisika model inkuiri terbimbing berbantuan videoscribe pada materi kalor untuk meningkatkan hasil belajar siswa SMAN 1 Kedungwaru. JPPS (Jurnal Penelitian Pendidikan Sains), 5(2), 1039-1047.

Sears, S. J. (2002). Contextual teaching and learning: A primer for effective instruction. Indiana: Phi Delta Kappa International.

Selvianiresa, D., \& Prabawanto, S. (2017). Contextual teaching and learning approach of mathematics in primary schools. Journal of Physics: Conference Series, 895, 012171. https://doi.org/10.1088/1742$6596 / 895 / 1 / 012171$

Sugiyono. (2015). Metode penelitian kualitatif, kuntitatif dan R\&D. Bandung: Alfabeta.

Supriyono. (2018). Pentingnya media pembelajaran untuk meningkatkan minat belajar siswa SD. EduStream: Jurnal Pendidikan Dasar, 2(1), 43-48.

Suryawati, E., \& Osman, K. (2017). Contextual learning: innovative approach towards the development of students' scientific attitude and natural science performance. EURASIA Journal of Mathematics, Science and Technology Education, 14(1), 61-76.

Susialita, T. (2016). The development of audio-visual student portfolios (LKS) contextual teaching and learningbased (CTL) on sound chapter of science subject for deaf students. Jurnal Pendidikan IPA Indonesia, 5(2), 192-198.

Yusup, M., Aini, Q., \& Pertiwi, K. D. (2016). Media audio visual menggunakan videoscribe sebagai penyajian informasi pembelajaran pada kelas sistem operasi. Technomedia Journal, 1(1), 126-138.

Yuwandra, R., \& Arnawa, I. M. (2020). Development of learning tools based on contextual teaching and learning in fifth grade of primary schools. Journal of Physics: Conference Series, 1554, 012077. 